\title{
Short-term absence from industry III The inference of 'proneness' and a search for causes
}

\author{
P. FROGGATT \\ Department of Social and Preventive Medicine, The Queen's University, Belfast
}

Froggatt, P. (1970). Brit. J. industr. Med., 27, 297-312. Short-term absence from industry. III. The inference of 'proneness' and a search for causes. The abilities of five hypotheses ('chance', 'proneness', and three of 'true contagion' - as defined in the text) to explain the distributions of one-day and two-day absences among groups of male and female industrial personnel and clerks in government service are examined by curve-fitting and correlation methods. The five hypotheses generate (in order) the Poisson, negative binomial, Neyman type A, Short, and Hermite (two-parameter form) distributions which are fitted to the data using maximum-likelihood estimates. The conclusion is drawn that 'proneness', i.e., a stable 'liability', compounded from several though unquantifiable factors, and constant for each individual over the period of the study, is markedly successful in explaining the data. It is emphasized that some of the other hypotheses under test cannot be unequivocably rejected; and there is in theory an infinite number, still unformulated or untested, which may be acceptable or even fit the data better.

Correlation coefficients for the numbers of one-day (and two-day) absences taken by the same individuals in two equal non-overlapping periods of time are of the order 0.5 to 0.7 $(0.3$ to 0.5 for two-day absences) and the corresponding regressions fulfil linear requirements. These correlations are higher than any between 'personal characteristics' and their overt consequence in contingent fields of human enquiry. For one-day absences the predictive power for the future from the past record could in some circumstances justify executive action.

When freely available, overtime was greatest among junior married men and least among junior married women.

The validity of the inference of 'proneness' and the implications of its acceptance are fully discussed. While interpretation is not unequivocal, one-day absences seemingly have many causes; two-day absences are also heterogeneous but in some ways resemble longer certified absence.

It is concluded that short-term absence, particularly of one day, may be largely the overt expression of a traditional desire, even need, to work discontinuously which, though it can be mitigated by often identifiable general and individual circumstances, is consistently more marked in some individuals than in others.

In two previous papers (Froggatt, 1970b, c) I have reviewed the literature, defined terms and described the data, delimited the study groups on the basis of sex, marital status, supervisory grade and employment class, and studied many statistics in these groups mainly of one-day and two-day absences but also of lateness, sickness absence, passes from work, age, length of service, and other factors. In the present paper I apply curve-fitting and correlation techniques to examine the adequacy of five plausible hypotheses adduced to explain the (discrete) distributions of one-day and two-day absences among the 
members of these groups. Such examinations are intended to elucidate the genesis of these events and to show how far the data may be used empirically to predict, from his previous record, an individual's likely future short-term absence experience.

There were two main problems in constructing this paper. First, to select, from over 50 sets of data used in the curve-fitting tests, a small number which could be considered characteristic; and second, to present the complex techniques and arguments in a form sufficiently detailed for coherence yet simple enough to be understood by those generally more concerned with the valid application than with the theoretical basis of analytical methods. The full results are given elsewhere (Froggatt, 1967, vol. 2); some aspects have also been dealt with by Froggatt (1964-5; 1970a).

I adopt the following presentation. First, I briefly review the literature of discrete distribution methods in studying absence from work; next, I set out the hypotheses under test and name the theoretical models which their assumptions generate; then I discuss the data and the analytical methods and present the chosen observed and theoretical distributions, their statistics, and the results of some further relevant tests; and, finally, I discuss the interpretation, implications, and practical application of the results, including those presented in the two previous papers of this study (Froggatt, 1970b, c).

\section{Literature}

Many authors have studied industrial morbidity though few have examined the form of the frequency distributions which generate the conventional rates (i.e., the numbers of persons having $0,1,2 \ldots$ absences, episodes of illness, etc.) despite the extra information which this may yield (Froggatt, 1968a). In the English-language medical literature only Snow (1913), Newbold (1926, 1927), Lundberg (1940), Russell, Whitwell and Ryle (1947), Sutherland and Whitwell (1948), Arbous and Sichel (1954a, b), Fortuin (1955), Hinkle, Pinsky, Bross and Plummer (1956), Hinkle and Wolff (1957), Lokander (1962), Simpson (1962), and Taylor (1967b) have used industrial morbidity in this way. (For a review of other sources see particularly Philipson $(1968 \mathrm{a}, \mathrm{b})$ and Kemp (1970)). Other authors have published data in the form of frequency distributions, e.g., some from the nineteenth century (see Froggatt, 1967, ch. 3) though most from the twentieth (e.g., Royal Commission, 1926, p. 367; Hill, 1929; Gafafer, 1940; Fox and Scott, 1943; and London Transport Executive, 1956), but they did not interpret the distributions obtained. All the above studies were on sickness absence; no one has examined short-term absence in this way.

Generally the distributions of individuals by the statistic of sickness used-usually 'number of absences' - has suggested that some individuals take more absences than do others and that a 'pure chance' hypothesis is untenable. Some have even introduced such concepts as 'sickness-repeater' (Gafafer, 1940), 'sickness-proneness' (Russell et al., 1947), 'absence-proneness' (Arbous and Sichel, 1954a), and 'tendency to sickness absence' (Lokander, 1962) as approximate analogues to 'accident proneness'. The first and last terms are merely convenient phrases; 'proneness', however, is an established hypothesis and the validity of its inference will form an important part of the discussion in this paper.

\section{Hypotheses and theoretical distributions}

The five hypotheses under test (A to $\mathrm{E}$ below) and the theoretical models generated on their assumptions have not previously been examined for their ability to explain the frequency distributions of short-term absences. I do not give the statistical derivation or properties of these models - these are considered in the works referenced with each: it is, however, emphasized that different assumptions may generate exactly similar models and this leads to interpretative difficulties, little stressed in medicostatistical writing, which are discussed in detail later. While I examine particularly the univariate distributions in association with the inter-period correlations, I also consider the bivariate case especially in relation to the negative binomial distribution as associated with hypothesis B below.

In the present context the five hypotheses may be stated as follows (for simplicity a one-day or two-day absence is designated an 'event'):

\section{Hypothesis A}

Random allocation of events in a homogeneous population in an environment either stable or which changes equally for all subjects.

Theoretical distribution: the Poisson (Poisson, 1837; Kerrich, 1951; Fitzpatrick, 1958).

\section{Hypothesis B}

$A b$ initio differences in the 'liability' of subjects, in an otherwise homogeneous group, to incur an event, the environment being either stable or changing equally for all subjects. Liability (conventionally symbolized $\lambda$ ) has a gamma (Pearson type III) distribution over the group and each individual's $\lambda$ remains unchanged. (Though the value of $\lambda$ for a given individual is hypothesized as strictly constant over the (usually relatively short) period of study, with the passing of time some change is generally assumed: see, e.g., Bates and Neyman (1952a)). This is the classical hypothesis of 'unequal liabilities' (Greenwood and Woods, 1919; Greenwood and 
Yule, 1920); for convenience it will be given below its more usual synonym of 'proneness'.

Theoretical distribution: the negative binomial (Greenwood and Yule, 1920; Newbold, 1927; Kerrich, 1951).

\section{Hypothesis C}

(1) Every subject, in an environment either stable or changing equally for all, is equally liable to 'spells' (periods of time) within which all events must occur. The number of spells in a given time is a Poisson variable with parameter $\lambda$ : this implies $(a)$ that the numbers of spells incurred by an individual in two periods are independent; and $(b)$ that the length of a spell is short in relation to the period of time under consideration.

(2) The probability of an event occurring within a spell is constant and not dependent on the individual: thus events within spells have a Poisson distribution with constant parameter $\theta$.

(3) No events can occur outside spells.

Theoretical distribution: the Neyman type A (Neyman, 1939; Cresswell and Froggatt, 1963; Kemp, 1967).

\section{Hypothesis D}

Similar to hypothesis $\mathrm{C}$ only now relaxing assumption (3) to allow events to occur outside a spell, in which case they are independently distributed as a Poisson variable with parameter $\phi$ over the given time period: thus they occur independently both of one another and of events within spells.

Theoretical distribution: the 'Short' (Cresswell and Froggatt, 1963; Kemp, 1967).

\section{Hypothesis E}

Events occur in 'clusters' which are randomly distributed among the subjects at equal risk. Only one or two events can occur in each cluster and such events follow a binomial distribution within clusters. Clusters and events are independent. Randomly distributed events can occur which are not members of a cluster but these cannot be identified from the distribution.

Theoretical distribution: the Hermite (twoparameter form) (Kemp and Kemp, 1965; 1966).

A priori hypotheses A and B are coherent for both one-day and two-day absences: so also are hypotheses $C$ and $D$ if we accept that spells relate to, say, periods of minor ill-health or perhaps low employee morale during which an individual incurs all his events (hypothesis $C$ ) or some of them with the others as independent random phenomena (hypothesis D), and also hypothesis $\mathrm{E}$ in that some clustering of oneday and two-day absences seems likely from the theories of genesis of these events. Other plausible hypotheses which generate distributions with well- studied properties (see, e.g., Patil and Joshi (1968) and Kemp (1970) for reviews) could have been examined but some restriction on numbers had to be imposed. The five selected $d o$ cover the three main classes of explanation for discrete events: 'chance' hypothesis A; 'proneness'- hypothesis $\mathrm{B}$; and 'true contagion' (see below) - hypotheses C, D, and E.

\section{Material and methods}

Data

Some 50 sets of data for each of one-day and two-day absences were fitted with the Poisson, negative binomial (for brevity subsequently designated NB) and Neyman type A distributions; 24 for each with the Short distribution; and 6 for each with the Hermite distribution. The first two models were also fitted to distributions of oneday absences by day of the week. For convenient presentation full results will be given only for G4 (largest male group) and G8 (females) for only one observation period; where necessary results from other groups will be summarized. In addition all 20 study groups (G1 to G12, M1 to M4, SC1 to SC4) supplied data for the correlation analyses - which are integral to the tests of the hypotheses - and essential summaries, mainly of the extensive previous results (Froggatt, 1970b, c), will be concisely presented.

It is again emphasized that pooling of groups to give larger samples would have produced (known) heterogeneity and been unacceptable for valid analysis, especially for the curve-fitting tests. The effect of age, previously shown to be significant in one-day absences (Froggatt, $1970 \mathrm{~b}$ ), could not be discounted in the selection: it is, however, extremely weak and since the relationship between the two factors could be accepted as linear rather than curvilinear no age group with aberrant experience could be identified and furthermore it would have been impossible to divide each study group (on the basis of age) into sub-groups of adequate size. As in the previous analyses, the consistency of the results over the groups is an important additional datum in appraising the results.

\section{Method of fitting the distributions}

The theoretical distributions were fitted to each set of data using computer-derived maximum-likelihood (M-L) estimates of the distribution parameters and a $\chi^{2}$ test of goodness of fit, pooling where necessary contiguous frequencies generally to give expected values of at least $5 \cdot 0$. Poisson frequencies were estimated directly; those for the negative binomial (NB) and Neyman type A were estimated from programmes based on solutions given by Haldane (1941) and Bliss and Fisher (1953) for the former and by Shenton (1949) and Douglas (1955) for the latter, while for the Short and Hermite frequencies Algol programmes were written on information previously given by Kemp (Kemp, 1967; Kemp and Kemp, 1965). Computing was done on the SRC Atlas and the Rothamsted Experimental Station Orion. Satisfactory convergence of the parametric estimates was everywhere achieved within the programmes' iterative instructions except on occasions with the Short distribution where the requirements, detailed by Kemp (1967), were not fulfilled and accordingly frequencies were not obtained. 
TABLE 1

Observed Frequencies of One-day Absences $\left(f_{\mathbf{x}}\right)$ and those Expected on the Poisson $(P)$, Negative Binomial (NB), Neyman Type A (NTA), Short, and Hermite Distributions using MAXIMUM-LIKELIHOOD ESTIMATES

(a) Group G4, 1957

\begin{tabular}{|c|c|c|c|c|c|c|c|c|c|}
\hline \multicolumn{4}{|c|}{ No. of absences $(\mathrm{x})$} & $f_{\mathbf{x}}$ & $P$ & $N B$ & $N T A$ & Short & Hermite \\
\hline $\begin{array}{r}0 \\
1 \\
2 \\
3 \\
4 \\
5 \\
6 \\
7 \\
8 \\
9 \\
\geqslant 10\end{array}$ & $\begin{array}{l}\ldots \\
\ldots \\
\ldots \\
\ldots \\
\ldots \\
\ldots \\
\ldots \\
\ldots \\
\ldots\end{array}$ & $\begin{array}{l}\ldots \\
\ldots \\
\ldots \\
\ldots \\
\ldots \\
\ldots \\
\ldots \\
\ldots \\
\ldots \\
\ldots\end{array}$ & $\begin{array}{l}. \\
\ldots \\
\ldots \\
\ldots \\
\ldots \\
\ldots \\
\ldots \\
\ldots \\
\ldots \\
\ldots \\
.\end{array}$ & $\begin{array}{r}27 \\
35 \\
35 \\
37 \\
19 \\
20 \\
10 \\
6 \\
3 \\
3 \\
0\end{array}$ & $\begin{array}{r}11 \cdot 9 \\
33 \cdot 3 \\
46 \cdot 6 \\
43 \cdot 4 \\
30 \cdot 3 \\
16 \cdot 9 \\
7 \cdot 9 \\
3 \cdot 2 \\
1 \cdot 1 \\
0 \cdot 3 \\
0 \cdot 1\end{array}$ & $\begin{array}{r}23 \cdot 4 \\
38 \cdot 5 \\
39 \cdot 6 \\
32 \cdot 6 \\
23 \cdot 5 \\
15 \cdot 5 \\
9 \cdot 5 \\
5 \cdot 6 \\
3 \cdot 2 \\
1 \cdot 7 \\
1.9\end{array}$ & \begin{tabular}{r|}
$25 \cdot 8$ \\
$36 \cdot 3$ \\
$38 \cdot 0$ \\
$32 \cdot 4$ \\
$24 \cdot 1$ \\
$16 \cdot 2$ \\
$10 \cdot 0$ \\
$5 \cdot 8$ \\
$3 \cdot 2$ \\
$1 \cdot 7$ \\
$1 \cdot 6$
\end{tabular} & \begin{tabular}{r|}
$26 \cdot 3$ \\
$34 \cdot 7$ \\
$38 \cdot 4$ \\
$32 \cdot 8$ \\
$24 \cdot 6$ \\
$16 \cdot 4$ \\
$10 \cdot 1$ \\
$5 \cdot 8$ \\
$3 \cdot 1$ \\
$1 \cdot 6$ \\
$1 \cdot 4$
\end{tabular} & $\begin{array}{r}25 \cdot 1 \\
32 \cdot 8 \\
40 \cdot 1 \\
33 \cdot 7 \\
25 \cdot 9 \\
16 \cdot 8 \\
10 \cdot 1 \\
5 \cdot 5 \\
2 \cdot 8 \\
1 \cdot 3 \\
1 \cdot 0\end{array}$ \\
\hline Total & . & . & . & 195 & $195 \cdot 0$ & $195 \cdot 0$ & $195 \cdot 1$ & $195 \cdot 2$ & $195 \cdot 1$ \\
\hline $\begin{array}{l}\chi^{2} \text { (D.F.) } \\
\mathbf{P} \quad \ldots\end{array}$ & $\begin{array}{l}. \\
.\end{array}$ & $\begin{array}{l}. \\
\cdots\end{array}$ & $\begin{array}{l}\cdots \\
\cdots\end{array}$ & & $\begin{array}{c}39.57(6) \\
<0.001\end{array}$ & $\begin{array}{l}4 \cdot 36(6) \\
0.5-0.7\end{array}$ & $\begin{array}{l}3.02(6) \\
0.8-0.9\end{array}$ & $\begin{array}{l}2.93(5) \\
0.7-0.8\end{array}$ & $\begin{array}{l}3.92(6) \\
0.5-0.7\end{array}$ \\
\hline
\end{tabular}

Mean $=2.795 \quad$ Variance $=4.608$

(b) Group G8, 1957

\begin{tabular}{|c|c|c|c|c|c|c|c|c|c|c|}
\hline & & $\mathbf{x}$ & & & & $\mathbf{f}_{\mathbf{x}}$ & $P$ & $N B$ & $N T A$ & Hermite \\
\hline $\begin{array}{r}0 \ldots \\
1 \ldots \\
2 \ldots \\
3 \ldots \\
4 \ldots \\
5 \ldots \\
6 \ldots \\
7 \ldots \\
8 \ldots \\
9 \ldots \\
10 \ldots \\
10 \\
11 \ldots\end{array}$ & $\begin{array}{l}\ldots \\
\ldots \\
\cdots \\
\ldots \\
\cdots \\
\cdots \\
\cdots \\
\cdots \\
\ldots \\
\cdots \\
\ldots\end{array}$ & $\begin{array}{l}\ldots \\
\cdots \\
\cdots \\
\cdots \\
\cdots \\
\cdots \\
\cdots \\
\cdots \\
\cdots \\
\cdots \\
\cdots\end{array}$ & $\begin{array}{l}\ldots \\
\ldots \\
\ldots \\
\ldots \\
\ldots \\
\ldots \\
\cdots \\
\ldots \\
\ldots \\
\ldots \\
\ldots\end{array}$ & $\begin{array}{l}\ldots \\
\ldots \\
\ldots \\
\ldots \\
\cdots \\
\cdots \\
\cdots \\
\cdots \\
\ldots \\
\cdots \\
\cdots\end{array}$ & $\begin{array}{l}\ldots \\
\ldots \\
\ldots \\
\ldots \\
\cdots \\
\cdots \\
\cdots \\
\cdots \\
\ldots \\
\ldots \\
\cdots\end{array}$ & $\begin{array}{r}21 \\
29 \\
17 \\
12 \\
4 \\
10 \\
6 \\
4 \\
2 \\
0 \\
1 \\
0\end{array}$ & $\begin{array}{r}9.6 \\
23.0 \\
27 \cdot 7 \\
22.2 \\
13.3 \\
6.4 \\
2.6 \\
0.9 \\
0.3 \\
0.1\end{array}$ & $\begin{array}{r}22 \cdot 3 \\
23 \cdot 8 \\
19.3 \\
14.0 \\
9.6 \\
6.3 \\
4 \cdot 1 \\
2.6 \\
1.6 \\
1.0 \\
0.6 \\
0.9\end{array}$ & $\begin{array}{r}22.3 \\
20.9 \\
19.7 \\
15.4 \\
10.9 \\
7.1 \\
4.3 \\
2.5 \\
1.4 \\
0.8 \\
0.4 \\
0.4\end{array}$ & $\begin{array}{r}21 \cdot 4 \\
17 \cdot 0 \\
24 \cdot 0 \\
15.5 \\
12.7 \\
7 \cdot 0 \\
4.4 \\
2 \cdot 1 \\
1 \cdot 1 \\
0.5 \\
0.2 \\
0.2\end{array}$ \\
\hline Total & . & . & . & . & .. & 106 & $106 \cdot 1$ & $106 \cdot 1$ & $106 \cdot 1$ & $105 \cdot 1$ \\
\hline $\begin{array}{l}\chi^{2} \text { (D.F.) } \\
\mathbf{P} \\
\ldots\end{array}$ & $\begin{array}{l}\cdots \\
\cdots\end{array}$ & $\begin{array}{l}\cdots \\
\cdots\end{array}$ & $\begin{array}{l}\cdots \\
\cdots\end{array}$ & $\begin{array}{l}\cdots \\
\cdots\end{array}$ & $\begin{array}{l}\cdots \\
\cdots\end{array}$ & & $\begin{array}{r}46.49(4) \\
<0.001\end{array}$ & $\begin{array}{r}7 \cdot 71(4) \\
0 \cdot 10-0 \cdot 20\end{array}$ & $\begin{array}{r}10.93(4) \\
0.02-0.05\end{array}$ & $\begin{array}{r}21.08(4) \\
<0.001\end{array}$ \\
\hline
\end{tabular}

Tests of the hypotheses

\section{One-day absences}

Evidence from fitting the distributions The following results were obtained for G1 to G8 over 1957, 1958 and 1957-8, and for some groups from company $M$; examples (frequencies rounded to one decimal place) for groups G4 and G8 and the relevant statistics are given in Tables 1 and 2. Throughout, a fit to the data is described as 'satisfactory' if the null hypothesis of concordance is not rejected at $\mathbf{P}=0.05$. (a) The Poisson was satisfactory in only one of 26 comparisons $(4 \%)$;

(b) the NB was satisfactory in 24 of 26 comparisons ( $95 \%$ ), the two exceptions being $\mathrm{G} 3$ over $1957\left(\chi^{2}=\right.$ $20 \cdot 62$, D.F. $=7,0.01>P>0.001)$ and G8 over $1958\left(\chi^{2}=9.68\right.$, D.F. $\left.=4,0.05>\mathrm{P}>0.01\right)$;

(c) the Neyman type A was satisfactory in 17 of 24 comparisons $(70 \%)$;

(d) the Short was satisfactory in 8 of the 10 comparisons $(80 \%)$ where frequencies were calculable - 
unimodal curves, the NB seems the most acceptable of the distributions tested though for the time being only the Poisson can be discarded. 1

The Short, despite its success in fitting the data and the coherence of its generating hypothesis $D$, will not be considered further. The reasons are technical: the parametric estimates have very large sampling errors which make them largely meaningless - and in terms of the physical model the negative estimates (e.g., in Table 2) are illegal; and the intercorrelations between the parametric estimates are very high ( $>0.99$ or $<-0.99$ ) which leads to difficulties in interpretation (Kemp, 1967).

Evidence from correlation Further information is provided by the correlations between the numbers of one-day absences incurred by the same individuals in two equal non-overlapping periods of time. The value of the correlation coefficient should not differ from zero on hypotheses A (see also Kemp's (1970) remarks on Maritz's (1950) idea of a correlated bivariate Poisson model) and C (Irwin, 1964) irrespective of the periods selected - and its value on hypothesis $\mathrm{E}$ has not yet been established (Kemp and Kemp, 1970); but on the strictest interpretation of hypothesis B ('proneness') it should be (a) positive and significantly different from zero, and independent of $(b)$ the periods selected and (c) their length, these results following from the postulated invariance of each individual's 'liability' $(\lambda)$. (This has been discussed by, e.g., Mintz and Blum (1949), Maritz (1950), and Blum and Mintz (1951) and the arguments have been reviewed by Fitzpatrick (1958)). Since, however, it is the overt consequence of $\lambda$, viz., short-term absences, which are the units, results $(b)$ and (c) follow only if the effect of any factor, not ascribable to $\lambda$ and acting non-systematically, is unimportant: '[on accident data] the inter-period correlation coefficients tend to fall as the interval between the two exposure periods increases perhaps one might expect this on the 'proneness' hypothesis: any correlation due to the personal factor would tend to get more and more diluted by increasing changes in environmental conditions of a non-systematic nature, affecting different subjects differently, and thus increasing the "chance" component' (Irwin, 1964).

I have already shown (Froggatt, 1970c) that (a) above holds - values of $\mathrm{r}$ are in the range 0.50 to $0 \cdot 70$, but that $(b)$ and $(c)$ may not - the inter-period correlations tend to decrease as the interval between the periods increases, and increase when the observation periods lengthen. Neither of these, however, discredits hypothesis $\mathbf{B}$, and in fact results obtained

${ }^{1}$ The Neyman and Hermite can, even with large samples, give unimodal curves with discrete data which are adequately described by a negative binomial, e.g., traffic accidents (Froggatt, 1970a). The reason is not clear at the moment. under $(b)$ are equivocal. The decrease in $r$ as the inter-period interval increases - $(b)$ above - may be artifact due to bias introduced because the correlations in Tables 14 and 15 of Froggatt (1970c) are not fully independently derived or, if not artifact, it may simply evidence Irwin's (1964) suggestion (above) that some waning in the proneness component over time is to be expected. The increase in $\mathbf{r}$ as the observation periods lengthen - (c) above - cannot be unambiguously interpreted: all the arguments suggest that within certain limits it is to be expected with proneness and ascribable to the more even operation of non-systematic factors in longer periods, or even 'under certain circumstances ... merely as an artifact' (Fitzpatrick, 1958). Certainly variation in the inter-period correlations is the rule and has been noted for sickness episodes or absence from work by Snow (1913), Lokander (1962), and Taylor (1968), and for other contingent classes of data, e.g., industrial accidents (Farmer and Chambers, 1929; Farmer, Chambers and Kirk, 1933), traffic accidents (Farmer and Chambers, 1939; Häkkinen, 1958; Cresswell and Froggatt, 1963), and patient-doctor consultations (Froggatt et al., 1969). Provided such variation is not marked - and in the present study this is the case - and having regard to real-life conditions proneness need not be rejected (Irwin, 1964).

Evidence from bivariate analysis The analysis is extended by deriving, from the parameters of the NB distribution for one-day absences taken in a single period, the value which $\rho$ (the correlation coefficient between the numbers of one-day absences incurred in that and any other similar period, usually the one following) would be expected to take if proneness completely explained the facts, i.e., postulating 'proneness mixture - no contagion - no timeeffect' in Bates and Neyman's (1952a, b) terminology, and then (i) comparing $\rho$ with $r$, and (ii) using $\rho$ in linear regression to compare predicted with observed experience. Logically the assumptions for tests under (i) and (ii) lead to a symmetrical bivariate negative binomial (SBNB) as the model with $\rho$ also calculable from parameters $k$ for the double-period and $\mathrm{m}=\frac{1}{2} \mathbf{M}$, where $\mathbf{M}$ is the double-period mean; but this method is less valid being $a$ posteriori and moreover uses data from the very period (the second) for which prediction is to be made. (For further discussion see Arbous and Sichel (1954a).) This approach, based on a single period's data, has obvious value in prediction and has been studied, on the above and related assumptions, by many authors from the time of Newbold (1927) (see Kemp, 1970, for review); the treatment below is a simple application of the theory.

Following Newbold (1927), Arbous and Sichel (1954a) reach the solution 


$$
\rho=\mathrm{m} /(\mathrm{m}+\mathrm{k}),
$$

where $\mathrm{m}$ and $\mathrm{k}$ are the univariate NB parameters from the first period's data, and give the linear regression

$$
\tilde{\mathbf{y}}=\rho \mathbf{x}+\rho \mathbf{k},
$$

where $y$ is the predicted mean number of one-day absences in the second period for those with $\mathrm{x}=0$, $1,2, \ldots$ in the first. Using M-L estimators $\hat{k}$ and $\hat{m}$ for the first period we reach values of $\hat{\rho}$ to compare with $\mathrm{r}$, and y to compare with the actual array means $\bar{y}, \bar{y}$ following a linear regression as required (Froggatt, 1970c).

Table 4, cols. 2 and 3 , shows values of $r$, and $\hat{\rho}$ calculated from the parameters of the NB for the

\section{TABLE 4}

Observed (r) and Expected $(\hat{\rho})$ Correlation Coefficients between Numbers OF SHORT-TeRM ABSENCES IN 1957 AND 1958

\begin{tabular}{c|cc|ccc}
\hline \multirow{2}{*}{ Group } & \multicolumn{2}{|c|}{ One-day absences } & \multicolumn{4}{|c}{ Two-day absences } \\
\cline { 2 - 6 } & $\mathrm{r}$ & $\hat{\rho}(1957)$ & $\mathrm{r}$ & $\hat{\rho}(1957)$ & $\hat{\rho}(1957-8)$ \\
\cline { 4 - 6 } & & & 0.430 & 0.360 & 0.354 \\
G1 & 0.457 & 0.620 & 0.430 & 0.083 & 0.337 \\
G2 & 0.693 & 0.507 & 0.495 & 0.083 & 0.234 \\
G3 & 0.681 & 0.548 & 0.247 & 0.175 & 0.319 \\
G4 & 0.572 & 0.410 & 0.400 & 0.359 & 0.319 \\
G5 & 0.546 & 0.568 & 0.424 & 0.173 & 0.386 \\
G6 & 0.688 & 0.613 & 0.563 & 0.306 & 0.379 \\
G7 & 0.594 & 0.475 & 0.438 & 0.211 & 0.315 \\
G8 & 0.542 & 0.557 & 0.262 & - & 0.162 \\
& & & & & \\
\hline
\end{tabular}

first period. Testing, using Fisher's $\mathrm{z}$ method, ${ }^{1}$ shows discordance between $\mathbf{r}$ and $\hat{\rho}$ in only two of eight comparisons (G2 and 4 where $0.05>P>0.01$ ) in these two $\hat{\rho}<\mathrm{r}$ whereas Arbous and Sichel (1954a) 'repeatedly' found $\hat{\rho}>\mathrm{r}$; while generally $\tilde{y}$ agrees reasonably with $\bar{y}$ in the eight groups tested (Table 5

\section{TABLE 5}

Actual (ỹ) and Predicted (ỹ) Mean Numbers of One-day Absences per Person in the Following Period (1958) FOR those haVING $x=0,1,2 \ldots$

\begin{tabular}{|c|c|c|c|c|c|}
\hline \multicolumn{3}{|c|}{ Group G4 } & \multicolumn{3}{|c|}{ Group $G 8$} \\
\hline $\mathbf{x}$ & $\overline{\mathbf{y}}$ & $\tilde{\mathbf{y}}$ & $\mathbf{x}$ & $\overline{\mathbf{y}}$ & $\tilde{\mathbf{y}}$ \\
\hline $\begin{array}{l}0 \\
1 \\
2 \\
3 \\
4 \\
5 \\
6\end{array}$ & $\begin{array}{l}1 \cdot 52 \\
1 \cdot 88 \\
2 \cdot 20 \\
2 \cdot 46 \\
3 \cdot 52 \\
4 \cdot 65 \\
4 \cdot 70\end{array}$ & $\begin{array}{l}1 \cdot 65 \\
2 \cdot 06 \\
2 \cdot 47 \\
2 \cdot 88 \\
3 \cdot 29 \\
3 \cdot 70 \\
4 \cdot 12\end{array}$ & $\begin{array}{c}0 \\
1 \\
2-3 \\
4-5\end{array}$ & $\begin{array}{l}1 \cdot 19 \\
1.55 \\
2.45 \\
3.00\end{array}$ & $\begin{array}{l}1 \cdot 11 \\
1.64 \\
2.43 \\
3.49\end{array}$ \\
\hline
\end{tabular}
in the Preceding Period (1957)

${ }^{1}$ It is not yet clear if this is strictly valid. gives data from the largest male group (G4) and the female group (G8) as examples) though with the suggestion that the regression slopes for $\tilde{y}$ and $\bar{y}$ may not always be similar. Thus the predictive power is satisfactory, an important practical result which is discussed later.

Finally, we note that since the assumption of proneness leads to the symmetrical bivariate negative binomial as the bivariate model the marginal theoretical frequencies should approximate those of the observed bivariate frequency table. This has been shown to be the case in 15 out of 16 comparisons (groups G1 to G8; two marginal distributions each) indicating that the SBNB is appropriate (Froggatt, 1967, ch. XI). (Where a more sensitive test is required, discordance between the observed cell frequencies on the bivariate table with those expected on the SBNB - as calculated from the joint probability density function - can be tested by $\chi^{2}$.) On all the evidence, therefore, proneness can be accepted in explanation of the data.

\section{Two-day absences}

The examinations were repeated for two-day absences. Since these are infrequent events, data for single years had $\mathrm{x}=0$ as the modal class and converged rapidly to zero, thus being inappropriate for curve-fitting where discrimination between compound Poisson distributions (in Gurland's (1957) terminology) is required. Though single-year distributions were fitted, the results will not be presented here (they showed generally all but the simple Poisson to be successful); instead double-year periods are used because the mean number of events, and hence modal class, are now greater and allow better discrimination between the fitted distributions.

Curve-fitting to groups G1 to G8 over the doubleyear period 1957-8 showed (G4 is given in Table 6 as an example):

(a) the Poisson was satisfactory in only one of eight comparisons $(12 \%)$;

(b) the NB and Neyman were each satisfactory in seven of eight comparisons $(87 \%)$;

(c) the Short was satisfactory in all the four comparisons possible (the other four had at least one negative parameter) though some - including G4 in Table 6 - were fitted by moments which is inefficient; and

(d) the Hermite was satisfactory in the only two groups (G4 and G8) tested.

On these findings only the Poisson can be discarded. Furthermore, since the observed distributions generally converge to zero smoothly and each theoretical distribution is unimodal, it is impossible to discriminate between the other four (compound Poisson) distributions from the results of curvefitting alone.

The inter-period correlation coefficients for two- 
TABLE 6

Observed Frequencies of Two-day Absences $\left(f_{\mathbf{x}}\right)$ and those Expected on the Poisson $(\mathbf{P})$, Negative Binomial (NB), Neyman Type A (NTA), Short, and Hermite Distributions using MAXIMUM-LIKELIHOOD EsTIMATES

Group G4, 1957-8

\begin{tabular}{|c|c|c|c|c|c|c|c|c|c|}
\hline \multicolumn{4}{|c|}{$\mathbf{x}$} & $f_{x}$ & $P$ & $N B$ & $N T A$ & Short & Hermite \\
\hline $\begin{array}{r}0 \\
1 \\
2 \\
3 \\
4 \\
5 \\
6 \\
7 \\
8 \\
9 \\
10\end{array}$ & $\begin{array}{l}. \\
\cdots \\
\cdots \\
\cdots \\
\cdots \\
. \\
\cdots \\
. \\
\cdots \\
\cdots \\
.\end{array}$ & $\begin{array}{l}\ldots \\
\ldots \\
\ldots \\
\ldots \\
\ldots \\
\ldots \\
\ldots \\
\ldots \\
\ldots\end{array}$ & $\begin{array}{l}\cdots \\
\ldots \\
\ldots \\
\ldots \\
\ldots \\
\ldots \\
\ldots \\
\ldots \\
\ldots \\
\ldots \\
\ldots\end{array}$ & $\begin{array}{r}40 \\
49 \\
36 \\
32 \\
15 \\
11 \\
6 \\
1 \\
1 \\
1 \\
3\end{array}$ & $\begin{array}{r}21 \cdot 8 \\
47 \cdot 8 \\
52 \cdot 3 \\
38 \cdot 2 \\
20.9 \\
9 \cdot 2 \\
3 \cdot 3 \\
1 \cdot 1 \\
0 \cdot 3 \\
0 \cdot 1 \\
-\end{array}$ & $\begin{array}{r}41 \cdot 6 \\
47 \cdot 0 \\
37 \cdot 9 \\
26 \cdot 5 \\
17 \cdot 1 \\
10 \cdot 5 \\
6 \cdot 2 \\
3 \cdot 6 \\
2 \cdot 0 \\
1 \cdot 1 \\
1 \cdot 4\end{array}$ & $\begin{array}{r}42 \cdot 6 \\
42 \cdot 8 \\
38 \cdot 2 \\
28 \cdot 3 \\
18 \cdot 7 \\
11 \cdot 3 \\
6 \cdot 4 \\
3 \cdot 4 \\
1 \cdot 7 \\
0 \cdot 9 \\
0 \cdot 8\end{array}$ & $\begin{array}{r}35 \cdot 3 \\
54 \cdot 5 \\
43.4 \\
25 \cdot 1 \\
13 \cdot 4 \\
8.0 \\
5.4 \\
3.7 \\
2.5 \\
1.5 \\
2.2\end{array}$ & $\begin{array}{r}38.5 \\
40.6 \\
43 \cdot 3 \\
30 \cdot 6 \\
20 \cdot 3 \\
11.2 \\
5 \cdot 8 \\
2.7 \\
1.2 \\
0.5 \\
0.3\end{array}$ \\
\hline $\begin{array}{l}\chi^{2} \text { (D.F.) } \\
P\end{array}$ & $\begin{array}{l}\cdots \\
\ldots\end{array}$ & $\begin{array}{l}\ldots \\
\ldots\end{array}$ & $\begin{array}{l}\ldots \\
\ldots\end{array}$ & & $\begin{array}{c}28.77(4) \\
<0.001\end{array}$ & $\begin{array}{c}2 \cdot 19(5) \\
0.80-0.90\end{array}$ & $\begin{array}{c}2 \cdot 50(5) \\
0 \cdot 70-0.80\end{array}$ & $\begin{array}{c}7 \cdot 28(4) \\
0 \cdot 10-0 \cdot 20\end{array}$ & $\begin{array}{c}4 \cdot 69(4) \\
0 \cdot 30-0 \cdot 50\end{array}$ \\
\hline Paramete & & .. & $\ldots$ & & $\mathrm{m}=2 \cdot 190$ & $\begin{array}{l}\mathrm{k}=2.335 \\
\mathrm{~m}=2.190\end{array}$ & $\begin{array}{l}\lambda=2.813 \\
\theta=0.778\end{array}$ & - & $\begin{array}{l}a_{1}=1.055 \\
a_{2}=0.567\end{array}$ \\
\hline SE paran & neters & $\cdot$ & .. & & & $\begin{array}{l}\mathrm{k}=0.525 \\
\mathrm{~m}=0.148\end{array}$ & $\begin{array}{l}\lambda=0.581 \\
\theta=0.162\end{array}$ & - & $\begin{array}{l}a_{1}=0.216 \\
a_{2}=0.115\end{array}$ \\
\hline
\end{tabular}

day absences are positive and significantly different from zero (they range from 0.25 to 0.55 ) and are probably unaffected by the length of the interval between the periods and the length of the periods themselves (Froggatt, 1970c). These findings accord with proneness but not with the other hypotheses tested (hypothesis D is again not considered).

Finally, the univariate NB parameters for single years give values of $\hat{\rho}$ often much smaller than those of $\mathrm{r}$ (Table 4, cols. 4 and 5) - and therefore poor agreement between $\bar{y}$ and $\tilde{y}$-suggesting that prediction of future experience from the past record is less powerful than for one-day absences. This does not discredit proneness - in fact values of $\hat{\rho}$ estimated from the SBNB (Table 4, col. 6), though they are consistently smaller, check the $r$ values quite well; it can simply be ascribed to the instability of the statistics of such rare events as two-day absences over single years. Longer periods of the data would in practice be required. Proneness is again, therefore, an acceptable explanation of the observations.

\section{Discussion}

'Proneness' is likely to become freely discussed in the medical literature as facilities for distributional analysis develop. Though a simple concept, its inference from data is difficult and conclusions are seldom unequivocal. The following discussion, though simply presented, is therefore closely argued; more detailed recent treatment and development of the proneness concept are given in Froggatt (1970a) and Kemp (1970). For simplicity a one-day or twoday absence is designated an 'event'.

\section{Interpretation of the results}

Of those under test, hypothesis B (proneness) explains the data for both events best and is on all counts satisfactory. Its acceptance depends partly on the success of the negative binomial (NB) to fit the data. As is well known, however, this distribution may be generated on hypotheses other than proneness (see, e.g., Irwin, 1941; Anscombe, 1950) - 'and if we had a negative binomial and it was a good fit [accident] proneness may be involved or it may not' (Greenwood, 1949) - and consideration of the data and the genesis of short-term absences suggests that at least four confounding phenomena may have been operating whether or not proneness was present at all: (a) unequal 'exposure to risk' among members of a study group; (b) biased ascertainment of events; (c) a clustering or spells phenomenon (e.g., hypotheses $\mathrm{C}, \mathrm{D}$, and $\mathrm{E}$ ) operating in some instances; and $(d)$ so-called 'contagion', not in the medical sense but in the mathematical sense that the very fact of incurring an event makes that individual more (or less) likely to incur another.

As regards $(a)$, under the method (heterogeneous Poisson sampling) by which the NB as the proneness model is derived, if a study group in fact comprises 
several sub-groups of different 'exposure to risk' and events are distributed purely at random within each sub-group, then, provided the sub-group means are not identical, the overall distribution could be fitted by the NB without proneness operating at all. This holds for heterogeneity for any variable which affects the event studied and explains why every effort was made in this work to delimit as far as possible homogeneous groups. This fact is seldom recognized in medical literature and proneness is commonly (and invalidly) inferred from a successful negative binomial fit to grossly heterogeneous data. Some heterogeneity in source material is, of course, inevitable; careful selection can do no more than keep it minimal.

As regards $(b)$, this operates classically as the tendency to report (which confounds the tendency to have) phenomenon which has bedevilled much research into accident proneness. Such biased ascertainment could again produce a distribution fitted by the NB when in fact an unbiased ascertainment could produce a totally different distribution. Ascertainment in the present study was probably very nearly complete and therefore this source of heterogeneity should be unimportant.

As regards (c), if spells have the meaning postulated in hypothesis $C$, then, under certain conditions, the overall distribution of events can be negative binomial in form (Kemp, 1967). A successful fit with the NB is therefore interpretable in terms of spells or proneness even if the data be pure. Also, Irwin (1964) has noted that a successful fit with the Neyman type A ('spells' hypothesis C), as frequently occurred in this study, can also under certain assumptions be given a 'proneness' interpretation. We cannot therefore discriminate between proneness and spells from curve-fitting alone. The correlation and bivariate evidence strongly favours proneness as a general theory but spells may operate to some extent.

As regards $(d)$, if all subjects have ab initio equal 'liability' (conventionally $\lambda$ ) to incur an event but after a subject has incurred $\mathrm{n}$ events his 'liability' to have further ones changes so that $\lambda$ per unit of time is a linear function of n, i.e., an hypothesis of 'contagion', the resultant distribution can be an NB (see, e.g., Anscombe, 1950, and Bates and Neyman, 1952b). Thus contagion (increasing or decreasing $\lambda$ through time) and proneness (constant $\lambda$ through time) cannot be differentiated solely from a univariate NB fit to the data: theoretically they may be distinguished from testing the corresponding bivariate models but differentiation is unlikely to be achieved in practice (Kerrich, 1951; Bates and Neyman, 1952b; Fitzpatrick, 1958). Even if it were achieved, interpretation would still be equivocal because it is unfortunately a feature of 'contagious' distributions that more than one set of basically different assump- tions can lead to exactly the same model. We note, however, that on the contagion hypothesis above, the mean number of events incurred by a study group would increase (or decrease) over time if every individual's liability $(\lambda)$ increased or decreased; or if the $\lambda$ of some members increased and of others decreased the mean could remain unchanged but the variance and form of the distributions would alter. These are controverted by the present data including scrutiny of the individuals' records. Thus cuntagion (as hypothesized above) is unlikely to be operating generally and in fact seems a far too unsophisticated model for such an entity as short-term absences. Contagion, however, in a more general sense may operate on some individuals and act to dilute the proneness component; but there seems no simple way of identifying these confounding factors.

Despite its rigid assumptions proneness as a general theory is markedly successful in explaining those aspects of the data studied.

\section{Implications of the findings}

If proneness be accepted we should consider its coherence and implications. In the field of accidents, from which the hypothesis is borrowed, $\lambda$ (liability) was assumed to be interpretable physically as the (stable) nett result of personal characteristics (christened 'proneness' by Farmer and Chambers (1926), and 'personal tendency' by Newbold (1926; 1927)) and environmental factors: thus $\lambda$ 'contains, in most practical cases, as well as the actual personal tendency, any constant external differential risk affecting particular persons which may exist in the same occupational group.... We cannot, of course, by any statistical modification distinguish between that part of the $\lambda$ which is personal and that which depends upon constant external bias' (Newbold, 1927). ${ }^{1}$ By studying groups of subjects homogeneous for environmental factors it was argued, reasonably enough, that $\lambda$ would measure proneness; and, further, since $\lambda$ and its overt consequence (accidents in the context; short-term absences here) would necessarily be closely related, differences between subjects in the latter would be ascribable very largely to differences in their $\lambda$ s. Identification of individuals with high proneness - inferred ex post facto from the (accident) record-and the continuing search for factors which may distinguish them, is the corollary

${ }^{1}$ Though Farmer and Chambers (1926) coined the specific term 'accident proneness', Osborne, Vernon and Muscio (1922) had earlier searched for 'conditions which may reasonably be regarded as analogous to those rendering a worker specifically prone to accidents' (my italics). The term 'prone' in the sense of 'liable' was of course well established in medicine by that time: thus 'proneness to swoon' in scurvy (Anson, 1756), 'prone to inflammation' (Abernethy, 1804), 'prone to migraine or neuralgia' (Ballance, 1899) and many others. 
of this reasoning. (Detailed reviews of mainly accident proneness have been given from the medicostatistical (Froggatt and Smiley, 1964) and mathematical (Kemp, 1970) viewpoints.)

Short-term absences, however, have many distinguishable causes and it is unrealistic to conceive such a rigid common factor as proneness - certainly in its classical sense. It is also unnecessary to do so. In the NB as applied here $\lambda$ need only represent the nett effect of many factors contributing to, though not necessarily exclusively causing, short-term absences: these factors need not each be constant for an individual though their nett result must $e x$ hypothesi. Lambda $(\lambda)$ therefore can assume its original connotation as comprising 'a motley host of motives and factors which will be very difficult indeed to separate and measure' (Greenwood and Woods, 1919). The members of this 'motley host' cannot accurately be identified let alone be given quantities: for example, a one-day absence might involve contracting a (minor) ailment, deciding to stay off work that day and deciding to return the next, each of these being itself influenced by 'personal' and 'environmental' factors and their interactions. Moreover, contributing factors must exist which are not true components of $\lambda$, and these are not readily identifiable. It seems unlikely that these formidable problems in interpretation are soluble from analysis of the data alone.

Irrespective of its components we may, however, determine the relationship between $\lambda$ and its overt result $x$, viz., the actual number of one-day or twoday absences taken. Accepting the SBNB as the model we may calculate the posterior distribution of $\lambda$ for given $x$ by amending Kerrich (1951), Eq. 5.23, for our data and obtaining the function

$$
2[(\mathrm{k} / \mathrm{m})+2] \lambda
$$

which has a $\chi^{2}$ distribution with $2(\mathrm{k}+\mathrm{x})$ degrees of freedom. Evaluating with $\mathbf{k}=\hat{\mathrm{k}}$ for the doubleperiod, and $m=\frac{1}{2} M$ (where $M$ is the mean of the double period) we reach estimates - for group G4 as an example - for the $90 \%$ limits of $\lambda$ (at $P=0.95$ and 0.05 on the table of $\chi^{2}$ ) when $\mathrm{x}=0,1,2, \ldots$ (Table 7). Following Kerrich (1951), Eq. 5.16, we estimate $\hat{\rho}_{\lambda \mathrm{x}}$ for one-day and two-day absences respectively as 0.80 and 0.70 evidencing, as expected, concomitant variation between $\lambda$ and $\mathrm{x}$; but the limits of $\lambda$ overlap each other considerably through the values of $x$ (Table 7) so that, for example, we could not assert that an individual having (say) four one-day or two-day absences was necessarily more 'liable' (or 'prone'- with the qualifications discussed) to these events over the two years studied than an individual having none. While this may hold for longer observation periods - and examination of four years' data for groups G9 to G12 suggests that it might (Froggatt, 1967, vol. 2) - it would be unwise
TABLE 7

$90 \%$ Limits FOR $\lambda$ ON THE SBNB Distribution (1957 AND 1958) GIVEN THAT AN INDIVIDUAL INCURS $x$ Events over the DOUble-period of THE DATA

\begin{tabular}{r|cc}
\hline & \multicolumn{2}{|c}{$\lambda^{1}$} \\
\cline { 2 - 3 }$x$ & One-day absences & Two-day absences \\
\hline 0 & $0 \cdot 303-2 \cdot 123$ & $0 \cdot 112-1 \cdot 244$ \\
1 & $0 \cdot 482-2 \cdot 582$ & $0 \cdot 230-1 \cdot 613$ \\
2 & $0 \cdot 678-3 \cdot 024$ & $0 \cdot 367-1 \cdot 962$ \\
3 & $0 \cdot 885-3 \cdot 454$ & $0 \cdot 515-2 \cdot 298$ \\
4 & $1 \cdot 101-3 \cdot 876$ & $0 \cdot 673-2 \cdot 625$ \\
5 & $1 \cdot 324-4 \cdot 290$ & $0 \cdot 837-2 \cdot 945$ \\
6 & $1 \cdot 553-4 \cdot 698$ & $1 \cdot 006-3 \cdot 260$ \\
7 & $1 \cdot 787-5 \cdot 102$ & $1 \cdot 180-3 \cdot 570$ \\
8 & $2 \cdot 025-5 \cdot 501$ & \\
9 & $2 \cdot 266-5 \cdot 897$ & \\
10 & $2 \cdot 510-6 \cdot 290$ & \\
& &
\end{tabular}

${ }^{1} M-L$ Estimators One-day absences $\mathrm{k}=3 \cdot 230, \frac{1}{2} \mathrm{M}=2 \cdot 834$. Two-day absences $k=2.335, \frac{1}{2} M=1.095$.

to extrapolate from results for comparatively short periods to sustain a general argument.

We have therefore a factor $(\lambda)$ whose components we cannot identify and measure and which is itself in some ways poorly estimated from the number of events actually incurred. This is the stark situation facing researchers into proneness in every human field of enquiry and it goes a long way to explain the failure to identify characteristics of 'prone' individuals. Nevertheless we note that $\lambda$ itself, whatever may be its components, correlates more closely with short-term absence ( $\hat{\rho}_{\lambda \times}$ above) than is the case with, say, accidents - where $\hat{\rho}_{\lambda \mathrm{x}}$ is in the range 0.40 to 0.60 (Cresswell and Froggatt, 1963; Froggatt, 1970a) though less well than is the case with 'consultationproneness' in general practice where $\hat{\rho}_{\lambda x} \bumpeq 0.90$ (Froggatt, 1970a). We may speculate that with shortterm absences (and consultations) the higher correlations are due to a major part of $\lambda$ being the relatively stable attitude, make-up, or circumstances of the individual which, in interaction with 'environmental' factors, largely determines the decision itself: for example, perhaps a 'neurotic' temperament, overconcern with one's health, poor health per se, and also a lack of resolve, conscientiousness, and corporate loyalty. 'Personal' factors of this type must largely determine those classes of mainly 'voluntary' events to which short-term absences belong.

\section{The causes of short-term absence}

Since a conscious decision largely determines shortterm absences their 'causes' could in theory best be established by direct questioning of persons. This was initiated but abandoned because $(a)$ there was delay between ascertaining the absence and question- 
ing the individual and often the 'cause' was allegedly forgotten, $(b)$ reasons given were often untrue, (c) more than one reason was frequently offered ('I didn't feel well and anyhow my brother was coming from the country' - or - 'My brother was coming from the country and anyhow I didn't feel well') and allocation to a single-cause category would have been arbitrary, and $(d)$ persons showed an increasing resistance to this type of questioning. An indirect approach was therefore necessary. Ideally this would include interviews with employees selected on their short-term absence record, as Taylor (1968) has done with sickness absence, but this was impossible to organize (redundancy in company $\mathrm{G}$ was a major problem) and accordingly only recorded data could be used to any extent. Some 20 matched pairs ('good' and 'bad' short-term absence record) were interviewed in company $\mathbf{M}$ but the results were insufficient for informative analysis. In fact it seems unlikely that statistically acceptable groups could be identified for interview except in very large organizations and the appropriate study would necessarily demand a team approach.

Discussion on causes can conveniently take the form of answers to the following two questions:

(1) is it possible to identify and measure some of the components of $\lambda$ ?;

(2) is it possible to identify and measure other factors influencing short-term absences?

The components of individual liability

The study groups were homogeneous for sex, marital and job status, supervisory grade, and centre unit; since proneness operated equally in each group these factors per se did not determine the distributions. Age and length of service are two stable variables - stable in that each changed in an equal fashion for all study group members - which differed between individuals, but only age affected short-term absences and that to an unimportant extent. Age could, of course, have contributed to $\lambda$ and its effect on short-term absences could either have been disguised by the imprecision of the estimates of $\lambda$ (Table 7) or mitigated by some factor with a contrary effect. For example, deteriorating health with age could increase one's liability to short-term absence but this might be neutralized by concomitant development of, say, a sterner sense of duty or a stronger habit of work. Such mitigating effects, if stable, could be considered components of $\lambda$ or, if unstable, as additional to it: since they cannot be reasonably measured except on the criterion of shortterm absences (which is fallacious post hoc ergo propter hoc) either alternative or a mixture is possible. This illustrates in microcosm the problems in trying to partition $\lambda$, and hence understanding 'causes', by this type of approach.

A more general method is to examine whether the results fit expectation better if the components of $\lambda$ were mainly 'medical' than if they were mainly 'nonmedical' - an unsatisfactory but practical dichotomy - as follows.

One-day absences A summary of results is given in Table 8. Generally one-day absences were positively associated with lateness, two-day absences, and medical passes but were not associated with works passes and long-term sickness absence (more than 2 days). They were most prevalent on Mondays, least prevalent on Fridays, and reasonably uniform throughout the year. They were negatively associated with age but independent of length of service, and the

\section{TABLE 8}

Summary of Findings on Associations between $(a)$ Numbers of Short-term Absences and Other Variables Studied, and $(b)$ Experience of Lateness and Passes in Two Equal Periods OF TIME (INTER-PERIOD ASSOCIATIONS)

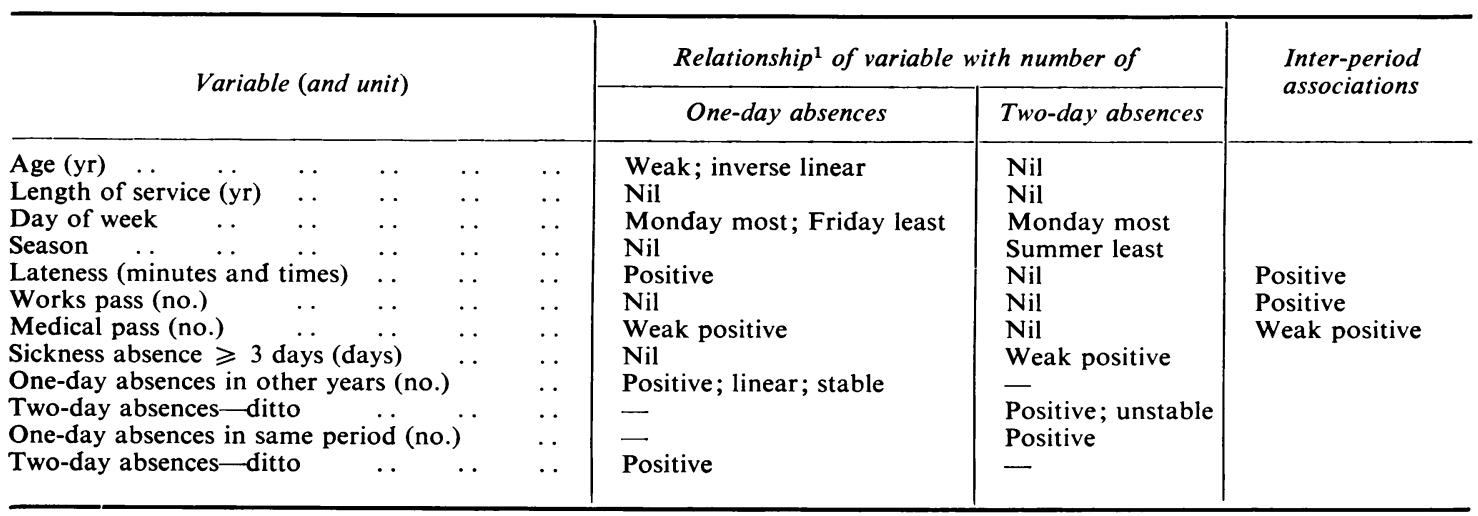

${ }^{1}$ Those given are for the generality. For individual departures see text in Froggatt (1970b, c). 
inter-period correlations were positive and of reasonable order and stability though they seemingly decreased as the interval between the periods increased and increased as the actual periods lengthened (Froggatt, 1970b, c). Except for the associations with medical passes and (negatively) with age - both very weak - and independence of works passes, these accord more with 'non-medical' than with 'medical' causes. Alternative interpretations, however, can be given (Froggatt, 1967, ch. XII): for example, the Monday peak may be due to genuine symptoms and not a reluctance to return to work; and the independence of (one-day) absences and (a) long-term sickness absence may be because minor illness need not mean more serious underlying disease, and (b) works passes may simply imply that 'non-medical' factors which prevent a person going to work are different from those which necessitate him leaving it (the marked inverse relationship between (low) numbers of one-day absences and (high) numbers of works passes on Fridays (Froggatt, 1970c) is a relevant datum). Only the association of one-day absences with lateness and medical passes-on respectively the 'non-medical' and 'medical' hypotheses - seem less equivocal. The evidence does not in fact unreservedly favour either hypothesis, a not unexpected conclusion.

Two-day absences A summary is given in Table 8 . These were positively associated with one-day absences and long-term sickness absence but were independent of medical and works passes and generally of lateness. They were most prevalent on Monday and least so on Thursday (Friday was omitted), and less common during the summer (May to August) than the rest of the year. Their interperiod correlations were positive though lower and less stable than those for one-day absences, and they were not associated with age and length of service (Froggatt, 1970b, c). Again, the evidence on either hypothesis ('medical' or 'non-medical') is contradictory. There are, however, important distinctions from one-day absences: the association of two-day absences with sickness absence (of 3 or more days), and its independence of lateness; the relative infrequency of two-day absences in the summer; and the fact that the inter-period correlations of respectively one-day absences and works passes were about equal - and sometimes seemed to be complementary phenomena, e.g., Friday experience - as were those of respectively two-day absences and medical passes. Without pressing the evidence too far two-day absences behave more like sickness absence than do one-day absences. One-day and two-day absences are themselves associated and so common factors should operate.

Other factors influencing short-term absences At its simplest the frequency of short-term absences is influenced by components of $\lambda$, by true random phenomena, and by other non-systematic factors either 'permanent' or 'temporary attributes' - in Thorndike's (1951) phrase - or somewhere on the continuum between them. Many such factors could affect short-term absences but those contributing to $\lambda$ and those additional to it could seldom be distinguished. Irwin (1964), in the analogous situation of accident-proneness, considers the allocation of factors often to be a matter of opinion: 'But suppose a man drives after drinking: is this to be taken as increased "exposure to risk" or as a personal idiosyncrasy, or as a chance event? Opinions might differ'. We must recognize this to be also the case in short-term absences. Nevertheless, information can be obtained from accepting a working dichotomy of (a) factors affecting all or most group members, and (b) factors affecting some.

As regards (a), investigators recognize 'local' and 'general' factors as influencing absence from work. Main examples of the former are (i) physical conditions of work (Baldamus, 1951), (ii) size of primary work unit (Hewitt and Parfit, 1953; Acton Society Trust, 1957), (iii) local level of employment (Long, 1951; Behrend, 1959), (iv) local wage rates and differentials (Vernon and Bedford, 1931, p. 5; Florence, 1949, pp. 98 et seq.; Liddell, 1954b; Shepherd and Walker, 1958); and of the latter are (v) occupation (Walker and Guest, 1952; Shepherd and Walker, 1957), (vi) day of the week of pay-day (Liddell, 1954a; Behrend, 1959), (vii) size of industrial unit (Acton Society Trust, 1953; Behrend, 1953), (viii) company morale (Acton Society Trust, 1957), and (ix) climate and/or season (Liddell, 1954b; Behrend, 1959). In the present instance selection of the sources and study groups made allowance for (i), (v), and (vi) and also largely discounted the rest. Differences in some of these could account for, say, any inter-group difference in the mean number of short-term absences, as was observed in this study (Froggatt, 1970c), but they could not have been responsible per se for the evidence adduced for proneness because this was constant in each group.

As regards $(b)$, many examples could be cited (see Behrend (1959) for review) the most germane perhaps being (i) sex, marital status, and supervisory responsibility (Froggatt, 1970b), (ii) outside responsibilities (Kahne et al., 1957; Shepherd and Walker, 1958), (iii) age and length of service (Kossoris, 1948; Kahne et al., 1957; Froggatt, 1970b), (iv) social environmental factors (Liddell, 1954b), (v) psychological and associated factors (Behrend, 1959), and (vi) overtime. Selection of the groups in this study standardized for (i), allowed the examination of the effect of (iii), but for the reasons given no substantial data were collected on (ii), (iv) or (v).

Information on overtime, however, was obtained for groups from centre unit $F$ for 1959, a year when 
overtime was fairly freely available. Analysis showed that age $\left(x_{1}\right)$, length of service $\left(x_{2}\right)$, and number of one-day absences $\left(y_{1}\right)$ were not associated with the number of weeks in which overtime was worked $\left(\mathrm{x}_{6}\right)$ (Table 9) - this latter measure being preferred ad

TABLE 9

Correlation Data between Age $\left(x_{1}\right)$, Length of Service $\left(x_{2}\right)$, Number OF ONE-DAy AbSences $\left(y_{1}\right)$, AND NUMBER OF WeEKS IN WHICH OVERTIME WAS WORKED $\left(\mathrm{x}_{6}\right)$

\begin{tabular}{l|ll}
\hline \multirow{2}{*}{ Correlates } & \multicolumn{2}{|c}{$\mathbf{r}($ centre unit $F, 1959)$} \\
\cline { 2 - 3 } & $J M M$ & $J S M$ \\
\hline $\mathbf{x}_{1} \mathbf{x}_{2}$ & $+0.703^{1}$ & $+0.744^{1}$ \\
$\mathbf{x}_{1} \mathbf{y}_{1}$ & -0.133 & -0.107 \\
$\mathbf{x}_{1} \mathbf{x}_{6}$ & -0.069 & -0.184 \\
$\mathbf{x}_{2} \mathbf{y}_{1}$ & +0.084 & +0.142 \\
$\mathbf{x}_{2} \mathbf{x}_{6}$ & +0.032 & -0.191 \\
$\mathbf{y}_{1} \mathbf{x}_{6}$ & -0.065 & +0.053 \\
$\mathbf{x}_{1} \mathbf{x}_{6} \cdot \mathbf{x}_{2}$ & -0.129 & -0.064 \\
$\mathbf{x}_{2} \mathbf{x}_{6} \cdot \mathbf{x}_{1}$ & +0.114 & -0.082 \\
\hline
\end{tabular}

${ }^{1}$ Significant at $P<0.001$ on normal theory.

interim to total hours of overtime worked because its distributional form is more appropriate to tests of correlation. Considering now in addition the number of hours of overtime per week in which overtime was worked $\left(x_{7}\right)$ leads to results in Table 10. The rank

TABLE 10

Mean Values of Measures of Overtime, $\overline{\mathbf{x}}_{6}$ AND $\overline{\mathbf{x}}_{7}$ (SEE TEXT)

\begin{tabular}{l|rc}
\hline Group & $\bar{x}_{8}$ & $\overline{\mathbf{x}}_{7}$ \\
\hline JMM & $12 \cdot 3$ & $7 \cdot 9$ \\
JSM & $8 \cdot 5$ & $6 \cdot 8$ \\
SMM & $7 \cdot 9$ & $6 \cdot 5$ \\
JSF & $4 \cdot 4$ & $6 \cdot 2$ \\
JMF & 4.4 & $4 \cdot 4$ \\
\hline
\end{tabular}

order of the groups is the same on each of $\bar{x}_{6}$ and $\bar{x}_{7}$ and the results show that males took more overtime than females, junior married men (JMM) clearly taking the most. The amount of overtime did not influence the total number of one-day absences taken; more elaborate data would be required to test more sophisticated hypotheses relating overtime to absences.

\section{Conclusions}

It seems unlikely that discrimination between general theories of 'causation' can ever be made from recorded data since no successful statistical model is likely to be unequivocal in interpretation: in fact no mathematical equation could completely explain such a complex situation as that of short-term absence. Nevertheless, proneness is a markedly successful hypothesis. Its corollary, i.e., searching for characteristics of 'high' and 'low liability' individuals would seem a fruitful exercise, particularly since the inter-period correlations are high and reasonably stable, more so in fact than are those for accidents where search for the 'accident-prone' has been energetically pursued. Identifying and measuring the characteristics of the 'one-day absence-prone' and the 'two-day absence-prone' would be of undoubted value to the vocational guidance counsellor, the employment officer, and the executive keen to reduce short-term absences by scientifically based measures over and above innovations which may have a general effect on the short-term absence level in his organization. Pragmatic business managers can note that irrespective of what the causes may be, reasonable prediction of likely average future experience, especially for one-day absences, can be made from that of the past (Table 5) though perhaps not to a power which would justify executive action through a tolerably low misclassification rate. (They may also note that the inter-period correlations for lateness (Froggatt, 1970c, Table 19-greater than 0.8 - are of an order where misclassification of individuals from their past experience may be acceptably low). In fact the inter-period correlations for one-day absences $(0.5$ to 0.7$)$ are larger than those generally obtained between any 'personal' characteristic and its overt consequence in contingent fields of human experience. Identifying factors correlating with shortterm absences, or the components of an individual's 'liability' $(\lambda)$, may therefore be largely of academic value; of practical significance is the fact that each individual's existing short-term (especially one-day) absence record could be the most informative datum on which to predict his likely future short-term absence experience. Application of such prediction theory to the problem of absence from work is detailed in Arbous and Sichel (1954b).

The results of this enquiry have limited application in practice. It would be an undeniable advantage to be able to identify, at the time of his employment, the potential bad attender because the disruptive effect of industrial short-term absences is out of proprotion to the actual time lost. It would also be an advantage to know what factors are associated with short-term absence and the strength of the relationships. Consequently it may be worthwhile continuing to search for a reliable and adequately powerful predictor which could be identified ideally before employment (the previous short-term absence record is seldom accurately known) whose power should of course be validated through prospective studies on 
other groups. This approach rather than a search for 'preventable' causes would seem the more profitable though whether any general executive action could be taken on the findings is open to doubt. Shortterm absence, whatever its alleged exciting cause, may simply be the overt expression of a desire to work discontinuously-as in a sense industrial history suggests - which, though it can be mitigated by general and individual circumstances, will still be more marked in some individuals than in others. Or, put another way, this proclivity to discontinuous work may be an inherent and not an adaptive attribute which can be modified but not radically altered by the environment. If this concept be accurate then conventional 'preventive' measures aimed not at groups as a whole but at the actual or potential bad attender, other than terminating or denying employment, are unlikely to be generally successful and often perhaps unjustified. Anyone interested in prevention must hope that this will not prove to be the case.

Many people too numerous to list helped in this inquiry. Thanks are due particularly to the managements of the two companies and the Director of Establishments of the Imperial Civil Service (Northern Ireland) who made the data available; to Dr. W. L. Cresswell, Dr. J. A. Smiley, Dr. P. D. Blackburn, and Dr. A. T. Park who helped in various ways, the first-named also assisting considerably in the tedious job of scrutinizing each attendance record and abstracting relevant data; to Mr. C. D. Kemp, Mr. R. Henry, Mr. R. Cordner, and Mr. T. J. L. Patterson who helped with computer programmes for The Queen's University and Short Bros. and Harland DEUCE computers and the S.R.C. ATLAS; to Mr. G. J. S. Ross and Mr. A. Barr who arranged facilities on respectively the Rothamsted Experimental Station ORION and the Oxford Regional Hospitals Board Elliott 803 computer; to Professor E. A. Cheeseman for much invaluable advice and guidance throughout; and to the Nuffield Provincial Hospitals Trust for financial assistance in connection with some of the computing. Without the cooperation and encouragement of the employers and unions this study could not have been attempted.

\section{References}

Abernethy, J. (1804). Surgical Observations; containing a Classification of Tumours ....; An Account of Diseases which strikingly resemble the Venereal Disease; And Various Cases illustrative of Different Surgical Subjects, p. 35. Longman and Rees, London.

Acton Society Trust (1953). Size and Morale: A Preliminary Study of Attendance at Work in Large and Small Units. The Acton Society Trust, London.

(1957). Size and Morale: A Further Study of Attendance at Work in Large and Small Units. The Acton Society Trust, London.

Anscombe, F. J. (1950). Sampling theory of the negative binomial and logarithmic series distributions. Biometrika, 37, 358-382.

Anson, Lord (1756). A Voyage round the World, in the Years 1740, $1741,1742,1743,1744,8$ th ed., p. 140. T. Osborne and others, London.

Arbous, A. G., and Sichel, H. S. (1954a). New techniques for the analysis of absenteeism data. Biometrika, 41, 77-90.

- (1954b). The use of estimates of absence-proneness for guiding executive action. Appl. statist., 3, 159-173.
Ashton, T. S. (1955). An Economic History of England: The Eighteenth Century, p. 214. Methuen, London.

Babbage, C. (1832). On the Economy of Machinery and Manufactures, etc. C. Knight, London.

Baldamus, W. (1951). Type of work and motivation. Brit. J. Soc., 2, 44-58.

- and Behrend, H. (1950). Variations in absenteeism during the week: An index of employee morale. Nature (Lond.), 165, 831-832.

Ballance, C. A. (1899). On certain affections of the ear. In A System of Medicine. Edited by T. C. Allbutt, 1896-1899, vol. VII, p. 579. Macmillan, London.

Bates, G. E., and Neyman, J. (1952a). Contributions to the theory of accident proneness. I: An optimistic model of the correlation between light and severe accidents. Univ. Calif. Publ. Statist., 1, 215-254.

- -1 (1952b). Contributions to the theory of accident proneness. II: True or false contagion. Univ. Calif. Publ. Statist., 1, 255-276.

Bedford, T., and Warner, C. G. (1931). Two Studies of Absenteeism in Coal Mines. II: A Study of Absenteeism at Certain Scottish. Collieries. Rep. industr. Hlth Res. Bd, No. 62, H.M.S.O., London.

Behrend, H. (1951). Absence under Full Employment. Studies in Economics and Society, Monograph A3. The University, Birmingham.

(1953). Absence and labour turnover in a changing economic climate. Occup. Psychol., 27, 69-79.

(1959). Voluntary absence from work. Int. Labour Rev., 79, 109-140.

Bennett, E. A. (1902). Anna of the Five Towns, p. 116. Chatto and Windus, London.

Bliss, C. I., and Fisher, R. A. (1953). Fitting the negative binomial distribution to biological data. Biometrics, 9, 176-200.

Blum, M. L., and Mintz, A. (1951). Correlation versus curve fitting in research on accident proneness: Reply to Maritz. Psychol. Bull., 48, 413-418.

Buzzard, R. B., and Liddell, F. D. K. (1963). Coalminers' Attendance at Work. Medical Research Memorandum No. 3, National Coal Board, London.

- , and Shaw, W. J. (1952). An analysis of absence under a scheme of paid sick leave. Brit. J. industr. Med., 9, 282-295.

Coats, A. W. (1958). Changing attitudes to labour in the mideighteenth century. Econ. Hist. Rev., 11 (2nd ser.), 35-51.

Cole, G. D. H. (1925). Robert Owen, p. 78. Ernest Benn, London.

Cresswell, W. L., and Froggatt, P. (1963). The Causation of Bus Driver Accidents: An Epidemiological Study. Oxford University Press, London.

Departmental Committee (1907). First Report of the Departmental Committee appointed to Enquire into the Probable Economic Effect of a Limit of Eight Hours to the Working Day of Coal Miners, Pt. I: H.C. 1907, Cd 3426, XIV. 525; Pt. II: 1907, Cd 3427 XIV. 529; Pt. III: 1907, Cd 3428, XV. 1. Final Report ..., Pt. I: 1907, Cd 3505, XV. 261 ; Pt. II: 1907, Cd 3506, XV. 349.

Douglas, J. B. (1955). Fitting the Neyman Type A (two parameter) contagious distribution. Biometrics, 11, 149-173.

Factories Inquiry Commission (1833). First Report . . ., H.C. 1833 (450) XX. 1.

(1834). Supplementary Report . ., H.C. 1834 (167) XIX. 253 ; XX. 1 .

Farmer, E., and Chambers, E. G. (1926). A Psychological Study of Individual Differences in Accident Rates. Rep. industr. Fat. Res. $B d$, No. 38. H.M.S.O., London.

_ _ - (1929). A Study of Personal Qualities in Accident Proneness and Proficiency. Rep. industr. Hlth Res. Bd, No. 55. H.M.S.O. London.

_- (1939). A Study of Accident Proneness among Motor Drivers. Rep. industr. Hlth Res. Bd, No. 84. H.M.S.O., London. , and Kirk, F. J. (1933). Tests for Accident Proneness. Rep industr. Hith Res. Bd, No. 68. H.M.S.O., London.

Fitzpatrick, R. (1958). The detection of individual differences in accident susceptibility. Biometrics, 14, 50-68.

Florence, P. S. (1949). Labour. Hutchinson's University Library No. 25 , London.

Fortuin, G. J. (1955). Sickness absenteeism. Bull. Wld Hlth Org., 13, 513-541.

Fothergill, A. (1796). An Essay on the Abuse of Spirituous Liquors, etc., p. 14. Bath.

Fox, J. B., and Scott, J. F. (1943). Absenteeism: Management's Problem. Graduate School of Business Administration Publication No. 29. Harvard University, Cambridge (Mass.). 
Friendly Societies (1852-3). Report and Tables, Prepared under the Directions of the Lords of the Treasury, by the Actuary of the National Debt Office, on the Subject of Sickness and Mortality among the Members of Friendly Societies, as shown by the Quinquennial Returns, to the 31st Day of December 1850, Received by the Registrar of Friendly Societies in England under the Provisions of the Act 9 \& 10 Vict., c. 27, H.C. 1852-53 (955) C. 295.

- - (1896). Special Report on Sickness and Mortality experienced in Registered Friendly Societies, together with certain Monetary Tables based thereon, by the Actuary to the Friendly Societies (Central Office), H.C. 1896 (303) LXXIX. 1.

Froggatt, P. (1964-5). One-day absence in industry. J. stat. soc. Inq. Society Ireland, 21, pp. 166-178.

- (1967). Short-Term Absence from Industry: A Statistical and Historical Study. Ph.D. thesis, The Queen's University, Belfast.

- (1968a). Research in industrial morbidity: principles and opportunities. Trans. Soc. occup. Med., 18, 89-95.

- (1968b). The East India Company (London Establishment): An early domiciliary industrial medical service. Trans. Soc. occup. Med., 18, 111-113.

- (1970a). Application of discrete distribution theory to the study of non-communicable events in medical epidemiology. In Random Counts in Scientific Work. Vol. 2. Edited by G. P. Patil, The Penn State Statistics Series, The Pennsylvania State University Press. In press.

(1970b). Short-term absence from industry. I: Literature, definitions, data, and the effect of age and length of service. Brit. J. industr. Med., 27, 199-210.

- (1970c). Short-term absence from Industry. II: Temporal variation and inter-association with other recorded factors. Brit. J. industr. Med., 27, 211-224.

(1970d). Short-term absence from industry. III: The inference of 'proneness' and a search for causes. Brit. J. industr. Med., 27, 297-312.

- -, Dudgeon, M. Y., and Merrett, J. D. (1969). Consultations in general practice: analysis of individual frequencies. Brit. J. prev. soc. Med., 23, 1-11.

_ and Smiley, J. A. (1964). The concept of accident proneness: a review. Brit. J. industr. Med., 21, 1-12.

Furniss, E. S. (1920). The Position of the Laborer in a System of Nationalism, pp. 119-120. Houghton Mifflin, Boston and New York.

Gafafer, W. M. (1940). Disabling morbidity among male and female industrial workers during 1938 and 1939, etc. Publ. Hlth Rep. (Wash.), 55, 1402-1406.

Gordon, C., Emerson, A. R., and Pugh, D. S. (1959). Patterns of sickness absence in a railway population. Brit. J. industr. Med., $16,230-243$

Greenwood, M. (1949). Discussion on Dr. Smeed's paper (Some statistical aspects of road safety research). J. roy. statist. Soc. A $112,25$.

, and Woods, H. M. (1919). A Report on the Incidence of Industrial Accidents upon Individuals with Special Reference to Multiple Accidents. Rep. industr. Fat. Res. Bd, No. 4, H.M.S.O., London.

- and Yule, G. U. (1920). An inquiry into the nature of frequency distributions representative of multiple happenings, with particular reference to the occurrence of multiple attacks of disease or of repeated accidents. J. roy. statist. Soc., 83, 255-279.

Gurland, J. (1957). Some interrelations among compound and generalized distributions. Biometrika, 44, 265-268.

Guy, W. A. (1843). An attempt to determine the influence of the seasons and weather on sickness and mortality. J. statist. Soc., 6, 133-150.

Häkkinen, S. (1958). Traffic Accidents and Driver Characteristics: A Statistical and Psychological Study. Scientific Researches No. 13, Finland's Institute of Technology, Helsinki.

Haldane, J. B. S. (1941). The fitting of binomial distributions. Ann. Eugen. (Lond.), 11, 179-181.

Hart, J. Y. (1922). An investigation of sickness data of public elementary school teachers in London, 1904-1919. J. roy. statist. Soc. $85,349-411$.

Hewitt, D., and Parfit, J. (1953). A note on working morale and size of group. Occup. Psychol., 27, 38-42.

Hill, A. Bradford (1929). An investigation of sickness in various industrial occupations. J. roy, statist. Soc, 92, 183-238.

Hinkle, L. E., Pinsky, R. H., Bross, I. D. J., and Plummer, N. (1956). The distribution of sickness disability in a homogeneous group of 'healthy adult men'. Amer. J. Hyg., 64, 220-242.

- , and Wolff, H. G. (1957). The nature of man's adaptation to his total environment and the relation of this to illness. Arch. intern. Med., 99, 442-460.

Inspector of Factories (1834). Revorts ..., H.C. 1834 (596) XLIII. 420.
- (1837). Reports ..., H.C. 1837 (73) XXXI. 53.

Irwin, J. O. (1941). Discussion on Chambers and Yule's paper (Theory and observation in the investigation of accident causation). J. roy. statist. Soc. Suppl., 7, 101-107.

(1964). The personal factor in accidents-a review article. J. roy. statist. Soc., $A, 127,438-451$.

J.M. (Montgomery, J.) (1832). The Carding and Spinning Master's Assistant, or the Theory and Practice of Cotton Spinning, p. 221. J. Niven Jun., Glasgow.

Kahne, H. R., Ryder, C. M., Snegireff, L. S., and Wyshak, G. (1957). Age and absenteeism. Arch, industr. Hith, 15, 134-147.

Kemp, A. W., and Kemp, C. D. (1966). An alternative derivation of the Hermite distribution. Biometrika, 53, 627-628.

Kemp, C. D. (1967). On a contagious distribution suggested for accident data. Biometrics, 23, 241-255.

(1970). 'Accident proneness' and discrete distribution theory. In Random Counts in Scientific Work. Vol. 2. Edited by G. P. Patil. The Penn State Statistics Series. The Pennsylvania State University Press. In press.

- and Kemp, A. W. (1965). Some properties of the 'Hermite' distribution. Biometrika, 52, 381-394.

,- (1970). Personal communication.

Kerr, C., Dunlop, J. T., Harbison, F. H., and Myers, C. A. (1962). Industrialism and Industrial Man: The Problems of Labor and Management in Economic Growth, pp. 193 et seq. Heinemann, London.

Kerrich, J. E. (1951). Accident statistics and the concept of accident proneness. Part II: The mathematical background. Biometrics, 7, 391-432.

Kidd, C. W., and Park, A. T. (1960). Sick leave among civil servants in the Northern Ireland government. Med. Offr, 103, 339-342.

Kossoris, M. D. (1948). Absenteeism and injury experience of older workers. Mth. Labor Rev. (Wash), 67, 16-19.

Langenfelt, G. (1954). The Historic Origin of the Eight Hours Day, Etc. Almquist and Wiksells, Stockholm.

Liddell, F. D. K. (1954a). The measurement of daily variations in absence. Appl. Statist., 3, 104-111.

(1954b). Attendance in the coal-mining industry. Brit. J. Soc., $5,78-86$.

Lokander, S. (1962). Sick absence in a Swedish company: A sociomedical study. Acta med. scand., 171, Suppl. 377.

London Transport Executive (1956). Health in Industry. A Contribution to the Study of Sickness Absence. Butterworth, London.

Long, J. (1951). Labour Turnover under Full Employment. Studies in Economics and Society, Monograph A2. The University, Birmingham.

Loveday, T. (1917). The causes and conditions of lost time. In Health of Munition Workers Committee. Interim Report: Industrial Efficiency and Fatigue, H.C. 1917-18, Cd 8511, XVI. 1019.

Lundberg, O. (1940). On Random Processes and their Application to Sickness and Accident Statistics. Almquist and Wiksells, Uppsala.

Maritz. J. S. (1950). On the validity of inferences drawn from the fitting of Poisson and negative binomial distributions to observed accident data. Psychol. Bull., 47, 434-443.

Marsh, H. H. (1967). Personal communication.

McKendrick, N. (1961). Josiah Wedgwond and factory discipline. Historical J., 4, 30-55.

Ministry of Fuel and Power (1948-9). Statistical Digest, H.C. 1948-49, Cmd 7548, XXIX. 595

Mintz, A., and Blum, M. L. (1949). A re-examination of the accident proneness concept. J. appl. Psychol., 33, 195-211.

Munition Workers Committee (1917-8). Interim Report: Industrial Efficiency and Fatigue, H.C. 1917-18, Cd 8511, XVI. 1019.

Neison, F. G. P. (1845). Contributions to Vital Statistics; being a Development of the Rate of Mortality and the Laws of Sickness from Original and Extensive Data procured from Friendly Societies, etc. Cunningham, London.

(1846). Contributions to vital statistics, especially designed to elucidate the rate of mortality, the laws of sickness, and the influences of trade and locality on health, derived from an extensive collection of original data, supplied by Friendly Societies, and proving their too frequent instability. J. statist. Soc., 9, 50-76. (1882). The Rates of Mortality and Sickness according to the Experience for the Five Years, 1871-1875, of the Ancient Order of Foresters Friendly Society, etc. Harrison, London.

Newbold, E. M. (1926). A Contribution to the Study of the Human Factor in the Causation of Accidents. Rep. industr. Fat. Res. Bd, No. 34. H.M.S.O., London.

- (1927). Practical applications of the statistics of repeated events, particularly to industrial accidents. J. roy. statist. Soc., 90, 487-535.

Neyman, J. (1939). On a new class of 'contagious' distributions, applicable to entomology and bacteriology. Ann. math. Statist., 10, 35-57. 
Norris, V. (1951). Health of the schoolchild. Erit. J. soc. Med., 5, 145-161.

Osborne, E. E., Vernon, H. M., and Muscio, B. (1922). Two Contributions to the Study of Accident Causation. Rep. industr. Fat. Res. Bd, No. 19. H.M.S.O., London.

Patil, G. P., and Joshi, S. W. (1968). A Dictionary and Bibliography of Discrete Distributions. Oliver and Boyd, Edinburgh.

Philipson, C. (1968a). A review of the collective theory of risk. I: Comments on the development of the theory. Skand. Aktuarietidskr., 51, 45-68.

- (1968b). A review of the collective theory of risk. II. List of literature on the theory of collective risk and related subjects. Skand. Aktuarietidskr., 51, 117-133.

Poisson, S. D. (1837). Recherches sur la Probabilité des Jugements, etc. Bachelier, Paris.

Pollard, S. (1963). Factory discipline in the Industrial Revolution. Econ. Hist. Rev. (2nd ser.), 16, 254-271.

Quenouille, M. H. (1952). Associated Measurements. Butterworth's Scientific Publications, London.

Report of Commissioners (1842). First Report of Commissioners for Inquiring into the Employment and Condition of Children in Mines and Manufactories. H.C. 1842 [380] XV. 1.

(1843). Second Report of Commissioners ... H.C. 1843 [430] XIII. 307.

Roll, E. (1930). An Early Experiment in Industrial Organisation; being a History of the Firm of Boulton \& Watt, 1775-1805, p. 222 (footnote). Longmans Green, London.

Rollins, H. E. (1922). A Pepysian Garland: Black-letter Broadside Ballads of the Years 1595-1639. Edited by H. E. Rollins, p. 445. University Press, Cambridge.

Royal Commission (1926). Report of the Royal Commission on National Health Insurance. H.C. 1926, Cmd 2596, XIV. 311.

Rusher, E. A. (1922). The statistics of industrial morbidity in Great Britain. J. roy. statist. Soc., 85, 27-71.

Russell, W. T., Whitwell, G. P. B., and Ryle, J. A. (1947). Studies in occupational morbidity (1). Brit. J. industr. Med., 4, 56-61.

Salzman, L. F. (1952). Building in England Down to 1540, etc., Ch. 2. Clarendon Press, Oxford.

Select Committee (1816). Report of the Minutes of Evidence taken before the Select Committee on the State of Children employed in the Manufactories of the United Kingdom. H.C. 1816 (397) III. 135.

- (1825). Laws respecting Friendly Societies. H.C. 1825 (522) IV. 321.

- (1873). Report of the Select Committee appointed to Inquire into the Present Dearness and Scarcity of Coal ..., H.C. 1873 (313) $\mathrm{X} .1$.

Shenton, L. R. (1949). On the efficiency of the method of moments and Neyman's type A distribution. Biometrika, 36, 450-454.

Shepherd, R. D., and Walker, J. (1957). Absence and the physical conditions of work. Brit. J. industr. Med., 14, 266-274.

- - - - (1958). Absence from work in relation to wage level and family responsibility. Brit. J. industr. Med., 15, 52-61.

Simpson, J. (1962). Sickness absence in teachers. Brit. J. industr. Med., 19, $110-115$.
Smith, M., and Leiper, M. A. (1936). Sickness Absence and Labour Wastage: Part I. Rep. industr. Hlth Res. Bd, No. 75. H.M.S.O., London.

Snedecor, G. W. (1946). Statistical Methods, 4th ed, The Iowa State College Press, Ames, Iowa.

(1956). Statistical Methods, 5th ed., The Iowa State College Press, Ames, Iowa.

Snow, E. C. (1913). Some statistical problems suggested by the sickness and mortality data of certain of the large Friendly Societies. $J$. roy. statist. Soc., $76,445-517$.

Sutherland, I., and Whitwell, G. P. B. (1948). Studies in occupational morbidity (2). Brit. J. industr. Med., 5, 77-87.

Taylor, P. J. (1967a). Shift and day work. A comparison of sickness absence, lateness, and other absence behaviour at an oil refinery from 1962 to 1965. Brit. J. industr. Med., 24, 93-102.

- (1967b). Individual variations in sickness absence. Brit. $J$. industr. Med., 24, 169-177.

- (1968). Personal factors associated with sickness absence: A study of 194 men with contrasting sickness absence experience in a refinery population. Brit. J. industr. Med., 25, 106-118.

(1969). Self-certification for brief spells of sickness absence. Brit. med.J., 1, 144-147.

Thomas, K. (1964). Work and leisure in pre-industrial society. Past and Present, No. 29, pp. 50-62.

Thorndike, R. L. (1951). The Human Factor in Accidents with Special Reference to Aircraft Accidents. U.S.A.F. School of Aviation Medicine, Rep. No. 1 (Project No. 21-30-001). Randolph Field, Texas.

Vernon, H. M., and Bedford, T. (1931). Two Studies of Absenteeism in Coal Mines. I: The Absenteeism of Miners in relation to Shorttime and other Conditions. Rep. industr. Hith Res. Bd, No. 62. H.M.S.O., London.

- - and Warner, C. G. (1928). A Study of Absenteeism in a Group of Ten Collieries. Rep. industr. Hlth Res. Bd, No. 51 H.M.S.O., London.

- and Rusher, E. A. (1920). Fatigue and Efficiency in the Iron and Steel Industry. Rep. industr. Fat. Res. Bd, No. 5. H.M.S.O., London.

Walker, C. R., and Guest, R. H. (1952). The Man on the Assembly Line, pp. 120 et seq. Harvard University Press, Cambridge (Mass.).

Watson, A. W. (1903). An Account of an Investigation of the Sicknes and Mortality Experience of the I.O.O.F. Manchester Unity during the Five Years 1893-1897, etc. The I.O.O.F. Manchester Unity, Manchester.

(1910). Some points of interest in the operations of Friendly Societies, Railway Benefit Societies, and Collecting Societies. $J$. Inst. Actuar., 44, 168-261.

- (1927). National Health Insurance: a statistical review. J. roy. statist. Soc., 90, 433-473.

Wyatt, S. (1945). A Study of Certified Sickness Absence among Women in Industry. Rep. industr. Hlth Res. Bd, No. 86. H.M.S.O., London.

-, Marriott, R., and Hughes, D. E. R. (1943). A Study of Absenteeism among Women. Emerg. Rep. industr. Hlth Res. Bd, No. 4. H.M.S.O., London.

Received for publication October 13, 1969 